\title{
Heritage Language and Cultural Preservation among the Nomadic Turkmen of Jordan: A Sociolinguistic Study
}

https://doi.org/10.33806/ijaes2000.20.1.12

\author{
Bader Dweik \\ Middle East University, Jordan \\ Isra' Abdelkhaleq \\ Islamic Scientific College, Amman, Jordan
}

\begin{abstract}
This study aimed to explore how the nomadic Turkmen of Jordan use Turkmen and Arabic in their daily life. It also describes the cultural aspects that they preserved and the factors that helped them in preserving their language and culture. Adopting the case study approach, a five-Turkmen-family sample served as participants utilising the participants'observation method and semi-structured interviews. Results revealed that the nomadic Turkmen of Jordan have maintained their ethnic language by using it exclusively at home with family members, grandparents and with relatives. They also preserved various aspects of their heritage culture such as clothing, life style, marriage and social traditions as well as their eating habits. Moreover, results have revealed some sociocultural factors that enhanced their language and cultural preservation such as partial isolation from the larger host community, rejection of external marriages, lack of education and the media.
\end{abstract}

Keywords: cultural preservation, factors, heritage language, Jordan, nomadic Turkmen

\section{Introduction}

The fact that language contact is an indispensable part of sociolinguistic studies is unquestionable. Thomson (2001: 1) defines language contact as "the use of more than one language in the same place at the same time". Language contact, she claims, "will inevitably lead to the change in languages as one language may influence the other". Final results of such language contact situations are usually crystallized as language change, language mixture or language death.

A major cause to language contact is involuntary immigration of ethnic minorities for various reasons. Language contact, of course, is always accompanied by cultural contact or even cultural clash. In such situations, minority groups either preserve their original cultural aspects or just fit in the new cultural context and lose their own cultural identity. The issue of languages in contact has always raised considerable interest among scholars and linguists. This study aims to answer the following questions:

1. How do the Turkmen of Jordan use Turkmen and Arabic in their daily life? 
2. What cultural categories (aspects) have the Turkmen of Jordan persevered?

3. What factors have helped the Turkmen of Jordan in preserving their language and culture?

\subsection{Who are the Turkmen of Jordan?}

The question of who the Turkmen are is not easy to answer. Sources vary not only in terms of the origins of Turkmen but also in the date of their arrival in Jordan. The Jordanian Turkmen are of two types according to their dates of settlement in Jordan. The first group is the sedentary who have lived in Jordan for many long years. This group historically settled in Marj Bani Amer and later moved to many other locations in Jordan and became known as the Arab Turkmen who integrated completely in the Jordanian society. The second group is the nomadic Turkmen who settled in Amman and its surroundings in recent years. Shoup (2007:8) maintains that "some of [the Turkmen] came with the Ottomans almost at the same time in which the Circassians and the Chechens arrived in Jordan". This nomadic group of Turkmen is the focus of this study and the findings are limited to it only.

According to the interviewed nomadic Turkmen of Jordan who participated in this study, they first settled in Al-Salt, Irbid and Ma'an in the time of Prince Abdullah I and in the 1970's they scattered in different parts of Amman i.e. Sahab, Albyader, Moqablein, Khrebet Assouq.

Matar (2010:132) stated that the number of the Turkmen living in Jordan does not exceed 5000. Their way of life has always been characterized by pastoral nomadic features. They generally live in tents, although some of them have newly built houses especially in Sahab. In the past, they depended on raising sheep, goats, camels and cattle. Nowadays, most of their men work as peddlers, as they sell cheap goods such as sunglasses, leather jackets, watches, belts and other items. Their women are usually housewives, while some of them work in collecting antiques that they sell later on. They keep moving from one place to another searching for their living. As a result, they do not usually send their children to schools due to their constant movement. They live in tribes and they are distinguished for their costumes and traditions. Women are usually dressed in colourful dresses called "fustan", while men are dressed casually in shirts and trousers. Their first loyalty is to the tribe, which is the largest descent group, then to the clan and finally to the family. The head of the group is called the "Sheikh", and usually he is the one that other members consult in any problem. This position is usually inherited by the sheikh's son after his death.

According to the interviewees, the Turkmen hardly ever have external marriages. Girls get married early at the age of 13-15, and even boys get married in relatively early ages. In many cases, they do not register their marriages legally in courts, unless the groom is of the legal age for marriage in Jordan. It is a must for them that a young man marries his cousin, the daughter of his father's brother.

They hold marriages in their neighbourhoods, and their parties are always mixed as men and women gather, sing and dance in the same place. One of the 
Turkish dances they perform is called "Anqara" dance in which dancers of two genders make a circle and dance. Long hair is usually a sign of women's beauty and they even use kinds of hair extensions to have the long hair they want. Women also cover their hair with a semi-transparent colorful piece of cloth called "mindeil". Rates of birth are relatively high as most of Turkmen have no less than ten children. It is a must for them to bring at least one male child to hold the name of his father as they said. In terms of food, some of them have preserved special kinds of Turkish food that they cook such as "Al masqouf " grilled chicken, homemade bread " baked on tannour", and dough with lentil. They drink sweet Turkish coffee, red and green tea, and other common boiled herbs. Very few of them are still keeping old ottoman pottery made of copper (personal communication).

\section{Review of literature related to language contact and language maintenance}

Weinreich (1974) elaborates on the issue of language in contact were he explores many linguistic phenomena that occur as a result of the existence of two languages in contact. These include bilingualism, linguistic interference as well as the socio-cultural setting of language in contact which all seem to be in the core of the current study.

He also states that "two or more languages will be said to be in contact if they are used alternatively by the same person" (p.1). A person who uses two different languages in different situations or with different people is called a bilingual, and the practice of using two different languages alternatively is called bilingualism. He also adds that interference is "the deviation from the norms of either language which occurs in the speech of a bilingual as a result of their familiarity with more than one language" (p.1).

What is even of more interest is that he relates language contact to cultural contact as only one facet of the larger phenomenon of cultural contact. Cultural interference involves both the death of some cultural aspects of any given group of people as well the as the adaptation of new cultural elements of the new society in which they live. Weinrich adds that "When a language contact situation is examined in details, the interrelation of socio-cultural conditions and linguistic phenomena are apparent" (p.38).

Fishman (1966) is one of the earliest sociolinguists to elaborate on different aspects of the issue of language and culture in contact. He defines both language maintenance and language shift as related topics to the issue of language stability and language change. He adds that there are many factors that may contribute to the preservation or loss of a language of any group of people. These include social, cultural and psychological factors.

Moreover, Fishman highlights three central sub-topics to be examined whenever the issue of language maintenance and language shift is investigated. These are:

1. The habitual use at more than one point in time or space under conditions of intergroup control. 
2. Psychological, social or cultural process related to stability or change in habitual language use under conditions of intergroup contact.

3. Behaviour towards language in contact settings. (p.424)

According to Fishman (1989: 202), there appear to be three major and recurring resolutions to interaction between two separate monolingual ethnolinguistic collectivities when such interactions are viewed from a perspective of more than three generations of time depth. If we take A to be indigenous and $\mathrm{B}$ to be intrusive in a particular setting then:

Resolution 1: $\mathrm{B} \rightarrow \mathrm{A}=\mathrm{A}$

Resolution 2: $\mathrm{B} \rightarrow \mathrm{A}=\mathrm{B}$

Resolution 3: $\mathrm{B} \rightarrow \mathrm{A}=\mathrm{B}+\mathrm{A}$

In Resolutions 1 the intrusive language is lost. In Resolutions 2 the indigenous language is lost. In Resolutions 3 both languages are maintained.'

Below is an illustration of these resolutions to make them clearer:

1. The host (indigenous) language dominates the intrusive language as the latter vanishes. An example is the case of English in England as it overcomes the language of immigrants from different parts of the world.

2. The immigrant language dominates the local (host) language as the latter dies out. An example is the case of the Native Indians in the United States as most of their languages were overcome by the immigrants' English language.

3. Both the host and the local language of a country coexist in the same social context as both of them are maintained while each is used in different domains.

Ferguson and Heath (1981) define language maintenance as "the preservation of the use of a language by a speech community under conditions where there is a possibility of shift to another language" (p. 530). On the other hand, they define language shift as "the change in regular use or mother tongue status of one language to another in a speech community" (p.530).

Winford (2003) discusses various types of language contact and suggests that these different results are the fruit of different social situations. That is the incident of language contact can only be understood through understanding the situation under which it was developed. Language contact's outcomes include language maintenance, language shift and language creation.

Clyne (2001) claims that home is a major factor for heritage language maintenance. He even gives the role of grandparents a superior position to that of parents as he states "grandparents rather than parents play an increasing role in the intergenerational language maintenance" (p. 367).

Empirically, researchers studied various minority groups in the Arab world (e.g. Dweik and Nofal 2013; Dweik and Al-Rahal 2015; Dweik, Nofal \& AlObaidi 2019). Jordanian groups also received attention in this regard as several studies shed light on the Chechens (Dweik 2000), the Circassians (Abdeljawad 2006), the Armenians (Al-Khatib 2001), The Druze ( Al-Zoubi 2007), the Kurds ( 
Al-Kurdi 2015), the Gypsies (Al-Khatib and Al-Ali 2005), and the Druze (AlKhatib and Alzoubi 2009) to name a few.

Dweik (2000) investigated linguistic and cultural maintenance among the Chechens of Jordan. The study explored language maintenance relationship to non-linguistic process that influences the outcomes of language contact situations. The sample of the study consisted of 100 subjects and the instrument included both questionnaires and interviews to collect data. Results of the study indicated that the Chechens of Jordan maintained their language and culture mainly because of their isolation from the larger Jordanian community. Chechen was thus used in most domains of language use including home, schools, neighbourhood religious and cultural settings. The study also concluded that the Chechens of Jordan maintained a diglossic use of Chechen and Arabic even through the third and fourth generation of them.

Al khatib and Al-Ali (2005), in their study on language and cultural preservation among the Gypsies of Jordan, found that there was a case of language maintenance among them. Data were collected from 100 speakers by the means of a questionnaire and interview. This linguistic-cultural preservation was attributed to the Gypsies isolation from the larger cultural community of the Jordanian. That they feel unable to melt in the overall cultural environment, the matter that led to the preservation to their own language and culture.

Al-Zoubi (2007) conducted a study that investigated language and cultural maintenance among the Druze of Jordan. It was a case study of the Druze of Ummal-Quttain village. The study aimed particularly to find out the socioeconomic, cultural, historical and religious factors that influenced cultural and linguistic maintenance among the Druze. Data were collected by the means of questionnaires and interviews that examined language proficiency, domains of language use and attitudes towards both languages. The findings of the study indicated that the Druze of Ummel-Quttain lived in both religious and social isolation from the majority Sunni Jordanian, the matter which enhanced cultural and linguistic maintenance.

Lui (2008) investigated maintaining Chinese as a heritage language in the United States. The study aimed to answer three main questions: what makes Chinese Americans maintain their heritage language? What factors are important for heritage language maintenance? And what difficulties do Chinese children face in preserving their heritage language? The sample of the study consisted of 28 participants, among them three were interviewed. Data were collected by the means of questionnaire and as well as follow-up interviews. The questionnaire was designed to reveal participants' opinions, attitudes and language learning experience about their heritage language maintenance. Results of the study revealed the following: both parents and their children had positive attitudes toward learning Chinese, Chinese children had difficulties in learning their heritage language due to the lack of interest and cross-language differences between Chinese and English and finally, family, extended family members and peers had a crucial role in heritage language maintenance. 
Rohani, Choi, Najm, Burnett and Colahan (2006) examined the role of family in language maintenance among immigrant families from six different backgrounds living in New York City. These were Persian, Spanish, Urdu, Japanese, Pakistani, and Cantonese speakers. The researchers interviewed six individuals of each group, and each interview lasted for around 60 minutes. Results of the study showed that family was the most crucial factor for language maintenance among the previous six groups. Both implicit and explicit actions were done by parents in order to help maintain their heritage language. Some of them moved to live in neighbourhoods where more immigrants of their groups live and use their heritage language and culture. Others sent their children to their homeland to spend time with relatives. Most of them bought specific materials to their children such as stories and books to help them practice their heritage language and even some of them verbally scolded their children for speaking English. Japanese parents used Japanese exclusively and Japanese mothers purposively did not learn English at the beginning at home as to force their children to use Japanese. Urdu speaking families stated that the existence of Urduspeaking home-maid who does not speak English helped in heritage language maintenance. The presence of grandparents among Cantonese speaking families fostered language maintenance as well.

\section{Methodology}

This paper adopts the case study approach. It examines a sociolinguistic phenomenon and aims at finding answers to "what" and "how" questions rather than finding statistical or quantitative information. Yin (2009: 4) reported that "the case study method allows investigations to retain the holistic and meaningful characteristics of real-life events". Moreover, this approach is found more suitable to the current study since it allows more direct contact as well as closer understanding of the target phenomenon and the target group. This is accomplished relying on the analysis of interviews' answers as well as observations that account for both verbal and non-verbal behaviour.

\subsection{The sample of the study}

A sample of five Turkmen families was selected as the researchers were assisted by a friend who introduced them to a photographer who is in direct contact with the studied group. The relatively small size of the sample is due to the difficulty of accessing the places of living of the investigated group and the nature of their life which is characterized by constant moving from one place to another in most cases. Therefore, results of the study may not be generalized beyond the sample and the instruments used in the study as well.

\subsection{The instruments of the study}

Two instruments were used. First, semi-structured interviews were designed following the method used in many previous studies such as in Park and Sarkar (2007), Otco (2008), and Dweik (1998) among others. They are favoured due to their flexible nature that provides a better chance to ask more questions that the 
context suggests (Cohen and Crabtree 2006). Interviews were held with common people of the community since the researchers could not find any key personalities among the studied group who hold high positions in Jordan. The researchers set the time and place of interviews in advance. The interviewees were Turkmen of both genders from different families living in various parts of the city of Amman. In general, the interviewees were cooperating and welcoming and they were even thankful for the researchers for examining their group. Five interviews were held with members of five different families. Two of them were with male members living in houses, and three with female Turkmen living in tents. Each interview lasted for almost an hour. After introducing herself and the purpose of the study, the female researcher started the interviews during which she took as many notes as possible. The interviewees were given the chance to speak freely without interruption, and thus the gained data were so valuable.

Questions of the interviews were arranged to cover a wide range of information. The interviews utilized three sections that helped to answer the questions of the study respectively. The first part of the interview dealt with how the Turkmen families used Turkmen and Arabic in their daily life. The second section examined the cultural aspects that the Turkmen of Jordan have preserved. Cultural aspects that were investigated included their dressing, food and drinks, style of living, marriage, music and art among others. The third part was designed to reveal the factors that helped them to preserve their language and culture.

The second instrument was observation. The efficiency and usefulness of observation as a means of data collection has been proved through both theoretical and empirical studies. Fraenkel, Wallen and Hyon (2012: 599) claim that while interviews provide the chance to reveal participants' thoughts and attitudes, "direct observation allows researchers to find out what they really do". This study used participant observation as the female researcher concentrated on observing language use among the five participants and their family members and observing their ways of life, their customs and some of their cultural facets that were obvious through observation.

After asking permission for camera recording from two separate families, the female researcher was able to videotape 90 minutes of the Turkmen daily life. Each family was videotaped for 45 minutes after the researcher asked them to act freely as if the camera was off. Summary notes were created on the day of each observation. All video recordings were saved in a locker at the researcher's home in order to insure their confidentiality and were only used for the sake of this study. Observation revealed that patterns of their use of Arabic and Turkmen, especially among parents and their children, for instance, were clearly seen. The same applies to their style of living, their costumes, the jobs they work in, their humble furnished tents and finally their friendliness and hospitality which were revealed through observation. 


\section{Results}

\subsection{Findings of language use among the Turkmen}

The first question of the current study aimed to find out how the Turkmen of Jordan use both Arabic and Turkmen in their daily interaction. To achieve this goal, the study used two instruments: interviews and observation. The participants in the interviews were asked several questions and their answers were recorded. The researchers focused first on language use at home with different family members. The first participant (32-year old female) said that she used only Turkmen with her little kids from the age of birth until they were grown up enough to mingle with other people outside home. With more grown up children, she mostly used Turkmen and sometimes used Arabic if there was a need to do so. In addition, she used only Turkmen with her spouse, siblings and parents. The second participant (42-year old male) used only Turkmen with all family members except with his grown up children with whom he used mostly Turkmen and sometimes Arabic. The third participant (32-year old female) said she used only Turkmen at home with all her family members; "we don't need Arabic at home, we only use it with strangers since they do not understand Turkmen", she said. The fourth participant (37-year old male) said he used only Turkmen with his little children, while he used both Arabic and Turkmen with his more grownup children. "It depends on what topic we are discussing. I usually shift to Arabic when the conversation is about an Arabic issue" he said. This applied also to his interaction with his siblings, spouse and parents, as he used mostly Turkmen and only shifted to Arabic when the topic required doing so. The fifth participant (45year old male) said he used only Turkmen with his little and grown up children as well as with his spouse, siblings and parents. "We hardly ever speak Arabic at home, it is not our home language, we inherited Turkmen from our parents and grandparents and now it's our role to keep it. Turkmen is our identity", he said. Table (1) summarizes home language use among the Turkmen of Jordan.

Table (1) Language Use at Home among the Turkmen of Jordan

\begin{tabular}{|c|l|c|c|c|c|}
\hline $\begin{array}{c}\text { Participant } \\
\text { number }\end{array}$ & $\begin{array}{c}\text { With little } \\
\text { kids }\end{array}$ & $\begin{array}{c}\text { With } \\
\text { grown up } \\
\text { children }\end{array}$ & $\begin{array}{c}\text { With } \\
\text { spouse }\end{array}$ & $\begin{array}{c}\text { With } \\
\text { siblings }\end{array}$ & $\begin{array}{c}\text { With } \\
\text { parents }\end{array}$ \\
\hline 1 & $\begin{array}{c}\text { Only } \\
\text { Turkmen }\end{array}$ & $\begin{array}{c}\text { Mostly } \\
\text { Turkmen }\end{array}$ & $\begin{array}{c}\text { Only } \\
\text { Turkmen }\end{array}$ & $\begin{array}{c}\text { Only } \\
\text { Turkmen }\end{array}$ & $\begin{array}{c}\text { Only } \\
\text { Turkmen }\end{array}$ \\
\hline 2 & $\begin{array}{l}\text { Only } \\
\text { Turkmen }\end{array}$ & $\begin{array}{c}\text { Mostly } \\
\text { Turkmen }\end{array}$ & $\begin{array}{c}\text { Only } \\
\text { Turkmen }\end{array}$ & $\begin{array}{c}\text { Only } \\
\text { Turkmen }\end{array}$ & $\begin{array}{c}\text { Only } \\
\text { Turkmen }\end{array}$ \\
\hline 3 & $\begin{array}{l}\text { Only } \\
\text { Turkmen }\end{array}$ & $\begin{array}{c}\text { Only } \\
\text { Turkmen }\end{array}$ & $\begin{array}{c}\text { Only } \\
\text { Turkmen }\end{array}$ & $\begin{array}{c}\text { Only } \\
\text { Turkmen }\end{array}$ & $\begin{array}{c}\text { Only } \\
\text { Turkmen }\end{array}$ \\
\hline 4 & $\begin{array}{l}\text { Only } \\
\text { Turkmen }\end{array}$ & $\begin{array}{c}\text { Mostly } \\
\text { Turkmen }\end{array}$ & $\begin{array}{c}\text { Mostly } \\
\text { Turkmen }\end{array}$ & $\begin{array}{c}\text { Mostly } \\
\text { Turkmen }\end{array}$ & $\begin{array}{c}\text { Only } \\
\text { Turkmen }\end{array}$ \\
\hline 5 & Only & Only & Only & Only & Only \\
\hline
\end{tabular}




\begin{tabular}{|l|l|l|l|l|l|}
\hline & Turkmen & Turkmen & Turkmen & Turkmen & Turkmen \\
\hline
\end{tabular}

Table (2) below shows how the Turkmen use language outside home in the following domains: neighbourhood, the work place, the worshiping place and media.

The first participant (32-year old female) said she used both Arabic and Turkmen in the neighbourhood and that she watched only Turkmen channels on TV. By contrast, she used only Arabic in her prayers since it is the language of the Holy Qur'an as she said. The second participant (45- year old male) said he used both Arabic and Turkmen in the neighbourhood depending on the person with whom he spoke. In the work place, he mostly used Arabic since his job as a peddler in an Arab country required that. In the worshipping place, he used only Arabic while he watched only Turkmen channels on TV. The third participant (32year old female) said she used mostly Turkmen in the neighbourhood unless a conversation was held with an Arabic speaker. She also used only Arabic in her prayers while she watched Turkmen TV channels only. The fourth participant (37year old male) said he used both Turkmen and Arabic in the neighbourhood while he mostly used Arabic in the work place. He did his prayers in Arabic while he watched Turkmen TV channels only. Finally, the fifth participant said he used mostly Turkmen in the neighbourhood while he used mostly Arabic in the work place. He watched both Arabic and Turkmen TV channels while he used only Arabic in his prayers. Summary is given in Table (2) below.

Table (2) Language Use Outside Home among the Turkmen of Jordan

\begin{tabular}{|c|c|c|c|c|}
\hline $\begin{array}{c}\text { Participant } \\
\text { number }\end{array}$ & $\begin{array}{c}\text { The } \\
\text { neighbourhood }\end{array}$ & $\begin{array}{c}\text { The work } \\
\text { place }\end{array}$ & $\begin{array}{c}\text { worshipping } \\
\text { place }\end{array}$ & $\begin{array}{c}\text { Language of } \\
\text { media (TV } \\
\text { Channels) }\end{array}$ \\
\hline 1 & $\begin{array}{c}\text { Arabic }+ \\
\text { Turkmen }\end{array}$ & ----- & only Arabic & $\begin{array}{c}\text { only } \\
\text { Turkmen }\end{array}$ \\
\hline 2 & $\begin{array}{c}\text { Arabic }+ \\
\text { Turkmen }\end{array}$ & $\begin{array}{c}\text { mostly } \\
\text { Arabic }\end{array}$ & only Arabic & $\begin{array}{c}\text { only } \\
\text { Turkmen }\end{array}$ \\
\hline 3 & $\begin{array}{c}\text { mostly } \\
\text { Turkmen }\end{array}$ & ---- & only Arabic & $\begin{array}{c}\text { only } \\
\text { Turkmen }\end{array}$ \\
\hline 4 & $\begin{array}{c}\text { mostly } \\
\text { Turkmen }\end{array}$ & $\begin{array}{c}\text { mostly } \\
\text { Arabic }\end{array}$ & only Arabic & $\begin{array}{c}\text { only } \\
\text { Turkmen }\end{array}$ \\
\hline 5 & mostly & mostly & only Arabic & $\begin{array}{c}\text { Arabic }+ \\
\text { Turkmen }\end{array}$ \\
\hline
\end{tabular}

As seen in Table (2) above Turkmen is used more often than Arabic in the neighbourhood and in media, while Arabic is the only language used in the worshipping place and is mostly used in the work place. 


\subsection{Findings of the cultural aspects that the Turkmen have preserved}

The interview questions related to the cultural aspects revealed a lot of interesting information. A major cultural manifestation that the Turkmen of Jordan have preserved is their clothing. The Turkmen women in particular are distinguished for the way they are usually dressed. They could not spare their traditional way of dressing despite their long residence in Jordan and their interaction with the outer Jordanian community. Turkmen women are known for their shiny colourful long dresses and their semi-transparent head covers. Moreover, they rarely cut their hair and wear it twisted most of the time. In addition, Turkmen women and even little girls have nose-ring accessory called (al-khuzum) which they inherited from their grandmothers.

Another aspect that the Turkmen of Jordan have preserved is their housing and life style. Most of them in general and most of the participants in particular (3\5) live in tents of different colours. Only two participants have recently built houses that are very humbly furnished in a way that resembles those of their old tents. Most of The Turkmen of Jordan still insist on living in tents, although many of them are not needy. They prefer to live in these tents since they lead a kind of nomadic life where they keep moving from one place to another searching for their living. One of the participants who had newly built a house asserted that he plans to keep his tent beside his house as he cannot be totally detached from the way he was raised up.

In terms of marriage traditions, all participants agreed that they usually get married at a relatively early age (15-18 for men and 13-15 for women). Dowries are usually very cheap, and the bride's father is the one who provides her with what she needs for marriage. Most of their marriages are not formally registered due to their illegal age of marriage. Most importantly for the current study, the interviewees have indicated that their marriages are all internal, and that there are very few cases of external marriages among them, if any.

Songs in wedding parties are a mixture of Turkmen and Arabic, and their parties are always mixed. The most popular dance is (Ankara dance) in which both men and women gather in circles, sing and dance.

Finally, the Turkmen have preserved certain types of ethnic food such as grilled chicken called (Masqouf), (Burghul) as well as their homemade bread (AtTanour).

\subsection{Finding and discussions of the factors that helped the Turkmen of Jordan to preserve their language and culture}

This cultural and linguistic preservation, as the researchers believe, can be attributed first to their pride in their identity. They showed positive attitudes towards their origins. This result is consistent with that of Park and Saker (2007), who found that parent's positive attitude and pride in their ethnic language and culture result in their maintenance over generations. Second, it can also be explained as a result of their partial isolation from the outer Jordanian community. As stated before, the Turkmen live in small groups which are scattered in different 
parts of Jordan. This "language island" has formed a kind of barrier that prevented their integration in the Jordanian community and thus enhanced their language and culture preservation. This result agrees with that of Dweik (2000), Al-khatib and Al-Ali (2005), and Al-Zoubi (2007) who examined relatively similar groups, i.e. the Chechens, the Gypsies and the Druze respectively, and found that major reasons for their language and culture preservation include their isolation from the outer community where they live and their internal marriages.

Furthermore, the family has played the main role in their language and cultural preservation. This includes the role of parents as well as those of grandparents. All participants of the current study stated that they spoke only Turkmen to their little children since birth, and thus it is the language that their children acquire naturally in their early years of childhood. Moreover, all participants spoke almost only Turkmen with their spouses, siblings and parents. This adherence to the use of a group's mother tongue over time results in preserving it from loss.

Moreover, some of the participants mentioned that keeping strong relations with the Turkmen such as speaking with friends and relative abroad have assisted in language and culture preservation. Many of them reported that they phone their relatives outside Jordan regularly. Others stated that they visit their relatives in Turkey constantly as they believe that their children should know more about their origins and culture.

This result goes hand in hand with results of many empirical studies, such as those of Lui (2008), and Rohani 'et al'. (2006) who found out that family in general and parents in particular have the upper hand in maintaining their heritage language among them and among their children as well.

Grandparents living in the same household with their Turkmen children and grandchildren had an important role in maintaining Turkmen through generations as well. Even some uneducated Turkmen's parents stated that they learned Turkmen alphabets from their grandparents. Moreover, participants who have a grandmother/father living with them reported that they keep using Turkmen with their grandchildren and that they tell them stories about their old incidents and about their history. This result agrees with many studies that highlight the role of grandparents in heritage language maintenance such as those of Lui (2008), who emphasize the role of grandparents in general and grandmothers in particular in language maintenance among their children and grandchildren.

Another factor that appears to have a noteworthy role in helping the Turkmen of Jordan to preserve their ethnic language and culture is their isolation from the outer Jordanian society. Despite their long residency in Jordan, the Turkmen of Jordan are forming a kind of subculture within Jordan. They are still keeping their own life style where they live in tents and keep moving from one place to another. Whether this is a matter of choice or is a consequence of being rejected by the larger community, it definitely contributes to the preservation of their ethnic language and culture. Their mixture with Arabic-speaking people is restricted to the work and worshipping places, and with time, they were able to 
learn the mainstream language Arabic orally. Furthermore, the Turkmen of Jordan do not send their children to schools because there are no schools that teach Turkmen in Jordan, they keep changing the places where they live and finally, those who tried to send their kids to public schools found that their children were not welcomed by other Jordanian children and were verbally abused -as they claimed-. This result is in line with that of Al-Zouby (2007), who examined language and cultural maintenance among the Druze of Jordan and concluded that their separation from the larger Jordanian community contributed to their preservation of their ethnic language and culture.

Similarly, Dweik (2000), who investigated language and cultural maintenance among the Chechens of Jordan, found out that they separated themselves from the larger Jordanian community, and consequently succeeded in maintaining their ethnic language and culture over the third and fourth generations. Finally, Alkhatib and Al-Ali (2005) also found out that the Gypsies of Jordan, who share many common grounds with the Turkmen, were also able to preserve their ethnic language and culture because they were unable to melt in the overall Jordanian cultural environment.

Media also have a strong role in helping the Turkmen of Jordan to preserve their ethnic language and culture. All participants stated that they watch Turkmen TV channels almost exclusively. One of them reported that one of their familial daily habits is to have lunch in front of the TV screen. This daily routine not only keeps them in connection with their ethnic language and culture, but it also strengthens their familial ties as well. Another participant asserted that watching Turkmen TV channels on the part of his children is doing a more profound role in helping them to know how to read and write Turkmen. Indeed, the aid of media is making the third and fourth generation more proficient in writing and reading skills than their parents. This result totally disagrees with theories that claim that language shift usually occurs within the third generation of immigrant groups. Undoubtedly, each linguistic situation should be studied individually taking into consideration all given circumstances that may affect the final result of either language maintenance or shift.

One more cause that is attributed to the maintenance of ethnic language and culture is the exclusive internal marriages the Turkmen of Jordan adhere to. All participants asserted that they never engage in external marriages; it is one of their fixed traditions that they stick to. They even exhibit more adherences to marriages among cousins. This tradition plays a crucial role in preventing any interference of any other language that might be spoken at home. Children who grow with Turkmen speaking parents will undoubtedly acquire Turkmen exclusively. In addition to language, cultural aspects are also better preserved since both parents share exactly the same background. This result agrees with those of Dweik (1998), who examined the language situation among the Yemenites of Lackawanna- New York and found that their internal marriages had a profound role in preserving their ethnic language.

The several visits that the female researcher paid to Turkmen-inhabited neighbourhoods and her 90 minutes tape-recording revealed many interesting 
facts related to the Turkmen of Jordan's language use and cultural preservation. In general, the researcher could clearly notice that almost all members of the investigated group communicated in Turkmen among each other. Little children (pre-school age) could not understand any word in Arabic; even when the researcher asked them very simple questions such as "where is your mum?" Or "what's your name?" in Arabic, they stared at her in a way that showed lack of the minimum degree of understanding. Children above six, on the other hand, showed more understanding of Arabic and were able to give simple answers to the researcher's questions. Moreover, adults (most of them are parents and grandparents) could smoothly converse with the researcher in Arabic although their accent showed that Arabic is not their mother tongue. They exhibited some kinds of language interference when they spoke Arabic as many of them did not use gender of pronouns correctly, and others used the third person pronoun "huwa" in Arabic to refer to themselves.

\section{Conclusion}

In conclusion the study showed that the Turkmen of Jordan have preserved their language and culture as illustrated by their use of Turkmen at home with parents, grandparents and children. It also showed that the use of Arabic language among them especially at home is absent. Additionally, the Turkmen have succeeded in preserving many aspects of their ethnic culture despite their long residency in Jordan. This is due to their style of living where the majority of them are still living in tents; their marriage traditions especially the early age of marriage, their outdoor mixed marriage parties and most importantly, their adherence to internal marriages.

Furthermore, the study identified many socio-cultural factors that enhanced language and cultural preservation among them. These factors include both immediate and extended family members. Parents and grandparents used only Turkmen with their children and grandchildren and encouraged them to feel proud of their ethnicity. Some parents paid regular visits to their relatives and friends abroad and thus were able to keep strong social relations with the Turkmen speaking members and exposed their children to their ethnic language and culture. Another factor is their partial isolation from the larger host community where they live on the sides of streets in their own tents and they could not totally melt in the outer Jordanian society. The media which include watching Turkmen TV channels have helped both parents and their children to stay in contact with their ethnic language and culture. Mobile networks also have a hand in facilitating constant interaction with other Turkmen-speaking relatives and friends abroad.

Among other factors that have played a role in the preservation of their language and culture include rejection of external marriages where they are not willing to get married to Jordanian Arab people. Finally the Turkmen of Jordan did not have an opportunity to get any kind of formal or informal education. Their nomadic style of living kept them constantly moving from one place to another, and thus they found difficulty sending their children to schools. As a result, they were 
not formally exposed to other languages. In fact, Turkmen is the language to which they are most exposed to since their early ages, the matter that gives it better chances to be preserved.

Acknowledgement: Our greatest thanks go to the wonderful Turkmen participants for their cooperation. A very special gratitude is extended to our colleagues for their valuable reviews and comments.

Bader Dweik

Middle East University, Jordan

Email: drdweik@hotmail.com

Isra' Abdelkhaleq

Islamic Scientific College, Amman, Jordan

\section{References}

Abdeljawad, Hasan. (2006). 'Why do minority languages persist? The case of Circassian in Jordan'. International Journal of Bilingual Education and Bilingualism, 9 (1):51-74.

Al-Khatib, Mahmud \& Abdulaziz Alzoubi. (2009). 'The Impact of SectAffiliation on Dialect and Cultural Maintenance among the Druze of Jordan: An Exploratory study'. GLOSSA, 4 (2):1-34.

Al-Khatib, Mahmoud and Mohammed Al-Ali. (2005). 'Language and cultural maintenance among the Gypsies of Jordan'. Journal of Multilingual and Multicultural Development, 26 (3):178-215.

Al-Khatib, Mahmoud. (2001). 'Language shift among the Armenians of Jordan'. International Journal of the Sociology of Language, 152:153-177.

Al-Kurdi, Lina. (2015). Language and Cultural Shift among the Kurds of Jordan: A Sociolinguistic Study. Unpublished MA Thesis. Middle East University, Amman, Jordan.

Al-Zoubi, Abd Al-Aziz. (2007). Language and cultural maintenance among the Druze of Jordan: A case study of the Druze of Umm Al-Quttain Village. Unpublished MA Thesis, Jordan University of Science and Technology, Irbid, Jordan.

Clyne, Michael. (2001).'Can the shift from immigrant language be reversed in Australia?'. In Joshua Fishman (ed.), Can threatened languages be saved? Reversing language shift: A $21^{\text {st }}$ century perspective, 364-389. Clevedon, UK: Multilingual Matters.

Cohen, Deborah. and Bernard Carbtree. (2006). Qualitative Research Guidelines Project. http://www.qualres.org/HomeSemi-3629.html (Retrieved on 13 June, 2016) 
Dweik, Bader and Mohammed Nofal. (2013). 'Language maintenance among the Indians of Yemen: A sociolinguistic study'. International Journal of Arabic /English Studies, 14:89-112.

Dweik, Bader and Sara Al-Rahal. (2015). 'Factors Enhancing Language Use in a Bilingual Turkmen Community in Baghdad'. Journal of language, linguistics and literature, 1 (6):175-181.

Dweik, Bader, Mohammed Nofal and Ma'alim Al-Obaidi. (2019). 'An Ethnic language and culture without a safe enclave: A Socio-cultural perspective'. International Journal of Arabic /English Studies, 19 (1): 103-022.

Dweik,Bader. (1998). 'Language loyalty among the Yemenites of Lackawanna/ New York'. AlBalqa Journal for Research and Studies, 5 (2): 12-31.

Dweik, Bader. (2000). 'Linguistic and cultural maintenance among the Chechens of Jordan'. Language, Culture and Curriculum, 13 (2):184-195.

Ferguson, Charles and Shirley Heath. (1981). Language in the USA. New York: Cambridge University Press.

Fishman, Joshua. (1966). Language Loyalty in the United States. The Hague: Mouton and Co.

Fishman, Joshua. (1989). Language and Ethnicity in Minority Sociolinguistic Perspective. England: Multilingual Matters LTD.

Fraenkel, Jack, Norman Wallen and Helen Hyon. (2012). How to Evaluate Research Education. New York, NY: McGraw-Hill Humanities, Social Science and Language.

Liu, Rong. (2008). 'Maintaining Chinese as a heritage language in the United States: What really matters?'. Arizona Working Papers in SLA \& Teaching, 15: 37-64.

Matar, Saleem. (2003). Jadal Al-Haowyat" Arab, Akrad, Turkman, Syriaan Yazzidiah: Sera'a Al-Intimaat fee Al-Iraq wa Al-Sharq Al-Awasat [identities debates: Arab, Turkmen, Assyrans, Yezidis: Conflict of Loyalties in Iraq and the Middle East]. Beirut, Lebanon: Arab Institute for Research and Publication.

Otco, Bahar. (2008). 'Heritage language maintenance and cultural identity formation: the case of Turkish Saturday school in New York City'. Journal of Heritage Language.7 (2): 112- 137.

Park, Seong and Mela Sarkar. (2007). 'Parents' attitudes toward heritage language maintenance for their children and their efforts to help their children maintain the heritage language: A case study of Korean-Canadian immigrants'. Language, Culture and Curriculum, 20 (3): 223-235.

Rohani, Sahba, Christine Choi, Rishm Najm Amjad, Christal Burnett, and Christopher Colahan. (2006). Language Maintenance and the Role of the Family amongst Immigrant Groups in the United Stated: Persian-Speaking Baha'is, Cantonese, Urdu, Spanish, and Japanese: An Exploratory Study. New York: Center for multiple Languages and Literacies (CmLL).

Shoup, John. (2007). Culture and Customs of Jordan. USA: Greenwood Press. Thomson, Sarah. (2001). Language Contact. Edinburgh: Edinburgh University 
Press.

Weinreich, Uriel. (1974). Language in Contact: Findings and Problems. The Hague: Mouton.

Winford, Donald. (2003). An Introduction to Contact Linguistics. Oxford: Blackwell Publishing.

Yin, Robert. (2009). Case Study Research: Design and Methods. Thousand Oaks, CA: Sage. 